\section{EUPEN Partners Sought}

As reported in Europhysics News $\mathbf{2 6}$

(1995) 69, the Scientific Committee of the Thematic Evaluation Conference - Physics Studies for Tomorrow's Europe (Ghent, 7-8 April 1995) decided to create a European Physics Education Network (EUPEN). A Steering Committee was formed and it has prepared an outline proposal for a Thematic Network in the framework of the SOCRATES programme of the European Union (EU). It will be submitted to the European Commission before 1 March 1996. Organizations throughout Europe, including all university-level physics faculties/departments, have been invited to join the initiative by completing a preliminary partnership agreement before 19 February 1996. Expresssions of interest were expected from least one institution in each EU country (except Luxembourg), in Norway, Iceland and Switzerland

(participation at their own cost), and in the east and central European countries (which may eventually receive support from the TEMPUS programme). Each participtaing institution is free to choose the level of involvement and the (related) willingness to supply complementary funding.

Societies and associations concerned with physics education (e.g., the EPS; national physical societies; associations for secondary school teachers, physics students and commercial companies) will be invited to join the network as Associate Members.

\section{EUPEN Project Outline}

The main initiatives envisaged are: - Continuation of comparability studies/ surveys/overviews of physics education in as many countries of Europe as possible, with a view to identifying the goals for physics teaching, and to establishing criteria to assess and promote quality in physics teaching to reach these goals (e.g., statistical data, structure of curricula, student and teacher workloads, teaching methods - both general and specific, notably laboratory practicals and the like, agreement on minimum requirements for entrance to university and for the first degree, etc.)

- Promotion of the European Credit Transfer Scheme in the field of physics leading to full mutual recognition of curricula by overcoming the existing difficulties for comparing student workloads in different countries. eligible for re-election:
- Promotion of inter-university cooperation with the view to identifying teaching centres for specialised subjects; the development and dissemination of new teaching techniques (open/distance learning, computer-aided instruction); the development of curricula, including the career aspect, post-graduate training (linked with the EC Training and Mobility of Researchers programme), and intensive specialised courses (refresher courses, courses for secondary school teachers and for managers from industry).

\section{Organization}

EUPEN will promote specific activities linked to these subjects, according to a predetermined schedule and a list of priorities. The actions needed to carry out the project will be organized by means of conferences and/or by a peer review system.

- The conferences would initially take the form of small workshops or discussion groups allowing individual contributions. Towards the end of the three-year period, meetings with a plenary lecture approach would be more appropriate.

- A Peer Review Committee (PRC) would be established for each subject chosen, with one to two representatives from each participating member, country or region plus experts and representatives from industry. The PRCs would prepare questionnaires for completion by participating institutions, analyse the results and gather complementary information through site visits. They would also jointly prepare and disseminate a final report and formulate the recommendations.
European Physics Education Network A Thematic Network for Physics

\section{Project outline}

http://allserv.rug.ac.be/ hferdin/eupen/proouthtml Preliminary Partnership Agreement

http://allserv.rug.ac.be/ hferdin/eupen/partner.html Information $\mathrm{H}$. Ferdinande

Vakgroep Subatomaire en Stralingsfysica,

Universiteit Gent, Proeftuinstraat 86, B-9000 Gent

E-mail hendrik.ferdinande@rug.ac.be

$\mathrm{Tel}+32-9-2646539 \quad \mathrm{Fax}+32-9-2646699$

Organizational details will be optimised once the level of involvement of each partner institution is know. The coordinator would be the University of Ghent. and a Steering Committee, grown out of the Scientific Committee of the Thematic Evaluation Conference on Physics will set up the necessary administrative structures (e.g., sub-networks specialised in one or more subjects of the project) as well as a convention for member institutions outlining quality and good practice.

\section{Results}

The main outcome would be: - Reports and/or proceedings of conferences and workshops made available to both member and non-member institutions and to interested organizations (governmental bodies, professional organisations, etc.) and publications specifying criteria and standards covering quality and good practice (electronic publication via the World-Wide Web is envisaged).

- The promotion and development of new teaching methodologies.

- Suggestions and recommendations for ways to tackle particular problems in specific countries.

\title{
EPS Interdivisional Group for Computational Physics
}

EPS Individual Ordinary Members who belong to the Computational Physics Group (CPG) are represented on the Group's Board by six delegates. Normally, a Board Member serves for one or two 3 -year periods. The terms of office of the following representatives end in 1996 and each has served two terms so none are

R.A. de Groot, University of Nijmegen M. Froissart, Collège de France, Paris W. Lauterborn, University of Göttingen J. Petersen, Norway

D. Stauffer, University of Cologne

Six new Board Members have to be elected this year. Nominations for candidates are sought. Candidates should be prepared to contribute actively to the Board meetings, which are held twice a year in various locations throughout Europe. It should be noted that travel assistance cannot be provided by the Group.

Candidatures should be sent before 31 March 1996 to the Secretary of the CPG, Jaroslav Nadrchal, Institute of Physics, Academy of Sciences, Cukrovarnicka 10, CZ162 oo Prague 6 (fax: +42-2-312 31 84; e-mail: nadrchal@fzu.cz). 